\title{
Techno-Economic Assessment of Polysaccharide Extraction from Baobab: A Scale Up Analysis
}

\author{
Maria Dimopoulou ${ }^{1,2}$, Vivian Offiah ${ }^{3,4} \mathbb{D}$, Kolawole Falade ${ }^{3,5}$, Alan M. Smith ${ }^{6} \mathbb{D}$, Vassilis Kontogiorgos ${ }^{1,7} \mathbb{D}$ and \\ Athanasios Angelis-Dimakis 2,*(D)
}

1 Department of Biological and Geographical Sciences, School of Applied Sciences, University of Huddersfield, Queensgate, Huddersfield HD1 3DH, UK; M.Dimopoulou@tees.ac.uk (M.D.); v.kontogiorgos@uq.edu.au (V.K.)

2 Department of Chemical Sciences, School of Applied Sciences, University of Huddersfield, Queensgate, Huddersfield HD1 3DH, UK

3 Department of Food Technology, University of Ibadan, Ibadan 200284, Nigeria; offiahvivian@gmail.com (V.O.); kolawolefalade@yahoo.com (K.F.)

4 Department of Food Science and Technology, Federal University of Agriculture, Makurdi 970231, Nigeria

5 Department of Food Science and Technology, Kwame Nkrumah University of Science and Technology, Kumasi, Ghana

6 Department of Pharmacy, School of Applied Sciences, University of Huddersfield, Queensgate, Huddersfield HD1 3DH, UK; a.m.smith@hud.ac.uk

7 School of Agriculture and Food Sciences, The University of Queensland, Brisbane 4072, Australia

* Correspondence: a.angelisdimakis@hud.ac.uk

Citation: Dimopoulou, M.;

Offiah, V.; Falade, K.; Smith, A.M.; Kontogiorgos, V.; Angelis-Dimakis, A. Techno-Economic Assessment of Polysaccharide Extraction from Baobab: A Scale Up Analysis. Sustainability 2021, 13, 9915. https:// doi.org/10.3390/su13179915

Academic Editor: Attila Gere

Received: 30 June 2021

Accepted: 30 August 2021

Published: 3 September 2021

Publisher's Note: MDPI stays neutral with regard to jurisdictional claims in published maps and institutional affiliations.

Copyright: (c) 2021 by the authors. Licensee MDPI, Basel, Switzerland. This article is an open access article distributed under the terms and conditions of the Creative Commons Attribution (CC BY) license (https:// creativecommons.org/licenses/by/ $4.0 /)$.
Abstract: This research studied the commercial exploitation of an indigenous African crop in order to formulate high value products, with a potential significant impact on the local economy. More specifically, the present work investigated the extraction of polysaccharides from baobab in a benchscale unit, focusing on the overall yield and the techno-economic assessment of the extraction process. Preliminary technoeconomic analysis for two scenarios (with and without ethanol recycling) was performed to determine the economic viability of the process and the development of the baobab market both in Nigeria and the UK. A full economic analysis was undertaken for each of the two scenarios, considering all operating and capital costs, and the production cost of baobab polysaccharides was estimated based on a constant return on investment. Combining the operating cost with the average polysaccharide yield, the minimum profitable selling price in the UK was estimated to be between $£ 23$ and $£ 35$ per $100 \mathrm{~g}$ of polysaccharide, which is comparable to the commercial selling price of high purity polysaccharides. An assessment of a scaled-up plant was also performed under Nigerian conditions and the results showed that such an investment is potentially viable and profitable, with a minimum profitable selling price of $£ 27$ per $100 \mathrm{~g}$, a value comparable to the UK-based scenarios.

Keywords: baobab; polysaccharide extraction; techno economic analysis; scale up; Nigeria

\section{Introduction}

Baobab (Adansonia digitata L.), which belongs to the Malvaceae family, is an indigenous African tree widespread in arid savannah regions of Madagascar, mainland Africa, the Arabian peninsula, and Australia, and it was once classified as the "lost crop" of Africa [1]. Baobab is a multipurpose tree and has attracted research interest from many industries, as most parts of the tree (fruits, leaves, bark, and seeds) can be used for either fodder, medicine, food, or to produce valuable utensils. The bark is soft and can be used to weave rope and clothes, whereas the fruit is one of the modern "superfoods". Only the baobab leaves remain unexploited and are only being used by the local population as part of their diet. For these reasons, it has been nicknamed as "the small pharmacy tree" or "chemist tree" [2]. In Africa, many parts of the baobab tree are consumed by humans for nutritional 
purposes. However, in Europe only the baobab fruit pulp is consumed and only since 2008, when the European Commission provided marketing authority as a novel food ingredient (2008/575/EC). Similarly, in the United States of America, it has been approved as a food ingredient since 2009 [3].

\subsection{Uses of Baobab}

The baobab fruit has an oblong or oval shape and consists of black seeds embedded in a chalky, white pulp $[4,5]$. The baobab fruit pulp is the most popular food source, as it contains high levels of calcium and is a ten times richer source of vitamin $C$ than oranges [6]. It is usually sold as a dry powder and when dissolved in milk or water, it can be used as a drink, food sauce, substitute for cream-of-tartar in baking, or fermentation agent in local brewing [6]. In addition, it is a significant source of polysaccharides and is low in protein. Because of the presence of saponins, sterols, and triterpenes, it has been traditionally used for analgesic, immuno-stimulant, pesticidal and anti-inflammatory purposes [7]. On an industrial scale, the baobab fruit is already being used in food and cosmetics applications, and there are a few companies that process and trade baobab fruit products worldwide.

On the other hand, baobab leaves are not yet authorised as a novel food in Europe and are only consumed in Africa. More specifically, baobab leaves are used in the preparation of soup and are a staple in Africa, due to the significant levels of minerals (e.g., iron, calcium, potassium, magnesium, zinc, and phosphorus). Young leaves are commonly used fresh or as a dried powder, and consumed as salad, or used to prepare sauces [8]. Furthermore, they are a significant source of essential and non-essential amino acids but also of vitamins $\mathrm{C}$ and $\mathrm{A}$. In addition, they consist of mucilage, which explains their traditional use as thickening agent in the African culture, and mostly in the Southern countries [9].

\subsection{Importance for the African Countries}

Smart and effective utilisation of indigenous agricultural resources is a key area, through which developing African country economies may grow. There is a continuous need to increase the agricultural production and, consequently, the income of farmers, who are pressured by international markets to maintain production at competitive prices. However, one major gap in the African agricultural sector is its inability to create and sustain export chains for agricultural produce, driven by poor knowledge of target markets. To that end, the commercial exploitation of an indigenous crop for the formulation of high value products might have an important economic impact to the local economy.

Baobab fruit is an ideal trade product for villagers, since the crops are light to transport, easily dried, and readily accessible. However, in the majority of countries it goes to waste because of the lack of demand and knowledge of the fruit properties. More specifically, baobab, as an important source of polysaccharides, has not been fully exploited due to limited information on its properties. With the knowledge gained from this research, polysaccharides that improve the performance of food systems could be developed. Furthermore, the application of baobab polysaccharides may not be limited to the food industry and could be expanded to the cosmetics and pharmaceutical industries.

Another significant impact that baobab can have to the local community is to help promote gender equality, since, traditionally, women are in charge of the baobab trees. An Africa-inspired health food brand and social business has been using baobab fruit as a key ingredient for their health and beauty products, in collaboration with Ghanaian partners. The company has been promoting the use of baobab worldwide, by developing an online campaign \#MakeBaobabFamous, showcasing the importance of the crop to the local society and economy. They state that over 1000 women have been working with them, either by harvesting the baobab fruits or in the processing centre. This has led to an increase in their annual income from $£ 9$ to $£ 119$, enabling the women to provide food, education, healthcare, and other basic needs for their families [10].

Focusing on Nigeria, which is the case study region for our research, an area of application for these polysaccharides could be the flour and baking industry. This would 
strengthen the use of indigenous flours and increase the income of local farmers. Nigeria's agricultural policies aim at accelerating industrialisation through research and development into utilisation and value addition of under-utilised agricultural commodities, such as baobab. This can lead to sustainable economic growth and employment, improved agricultural production and a new income source for small scale food producers or rural population who harvest and sell such commodities in local markets. During the past decade, the Nigerian Government initiated a policy on $10 \%$ cassava flour inclusion in bread, as part of efforts to boost the utilisation and create markets for farmers and small/medium scale processors. The program drove the demand for cassava, increasing productivity by approximately 10 million tonnes in six years, making, temporarily, Nigeria a top world producer. Similarly, baobab polysaccharides can be used as a natural improver in wheatcassava breads and subsequently increase the market demand for baobab.

\subsection{Research Objectives}

Functional polysaccharides, with their ability to modify rheology of food systems, can ultimately improve baking quality of composite flours and enhance the use of locally produced non-wheat flours. The industrial exploitation of polysaccharides depends on an understanding of their characteristics. Therefore, it is critical to isolate and characterise baobab polysaccharides, if they are to serve as raw materials in industrial applications and create value for Nigeria. An assessment of the economic viability of extracting such polysaccharides on a large scale is equally important, along with investigating the potential market for such products.

The present work evaluates the extraction of polysaccharides in a bench scale plant, focusing on the yield and the techno-economic assessment of the process. The objective was to determine indicative production costs of baobab polysaccharides under realistic scenarios and to estimate the minimum selling price of the polysaccharide in order to make the process economically viable. The novelty of this paper is not on the methodology used, but on the actual case study examined. To the best of our knowledge, there is no study in literature presenting both a technoeconomic assessment and a scale-up analysis of a polysaccharide extraction unit from baobab. Therefore, this study aims to pave the way for the development of the baobab market in Nigeria and other African countries. The positive results indicated by this study can lead to the wider exploitation of baobab leaves and crops and have a significant positive impact to the local economy. The development of new baobab processing plants can be supported by the findings of this study and new jobs can be created for the local workforce. Moreover, the development of the baobab market can give women a chance to harvest and sell their own product, increase their annual income, and reduce the social inequalities in the region.

\section{Materials and Methods}

The following section summarises the materials and methods used to isolate pectin from baobab on a bench scale unit. The reported parameters and the corresponding values are those that have been deemed critical for the technoeconomic analysis and the scale up process. Before the bench scale extraction, processing $1 \mathrm{~kg}$ of baobab, a smaller laboratory scale extraction, processing $100 \mathrm{~g}$ of baobab, was performed to optimise the process. The detailed description of both experimental methods as well as the physical and chemical properties of the extracted polysaccharides have been presented in [11].

\subsection{Materials}

Two different types of baobab varieties were examined: one with oblong and another with oval shape fruits. Moreover, two different parts of the baobab tree were analysed, i.e., leaves and fruits. Fresh baobab leaves and fruit pulp have been bought from local Nigerian markets. They have been processed (dried at $45^{\circ} \mathrm{C}$ and grinded to a fine powder) at the University of Ibadan in Nigeria and shipped to the University of Huddersfield for extraction and analysis. 
The isolation protocol used to extract polysaccharides from baobab was based on previous work of the authors on pectin extraction from lemons and arabinoxylans from sugarcane bagasse [12,13]. All buffer salts, monosodium phosphate monohydrate, disodium phosphate heptahydrate, sodium azide, isopropanol, and ethanol were of analytical grade and were purchased from Sigma Aldrich.

The bench scale plant, used for the polysaccharide extraction (Figure 1), consists of a mash tank (A), and a distillation column (B), part of the GUNT CE 640 Biotechnical Production of Ethanol unit. The unit is located at the Chemical Engineering lab of the School of Applied Sciences at the University of Huddersfield. The mash tank, used for the aqueous extraction process, is made of stainless steel and has a capacity of $60 \mathrm{~L}$ (cylindrical shape with maximum diameter of $341 \mathrm{~mm}$ and maximum height of $675 \mathrm{~mm}$ ). The contents of the tank can be heated either directly, by injecting steam from the bottom of the vessel through a jet (which leads to an increase of the liquid content by around 15\%), or indirectly, by circulating hot water (up to $80^{\circ} \mathrm{C}$ ) in the jacket of the vessel. The stirrer speed ranges from 105 to $200 \mathrm{rpm}$. The distillation unit is a modified boiler heater with water bath, with a capacity of approximately $40 \mathrm{~L}$. The still and the dephlegmator are made of copper whereas the condenser and the water bath are made of stainless steel. The stirrer speed is constant at $135 \mathrm{rpm}$. A programmable logic controller (PLC) controller is available in order to monitor and control the major experimental variables (temperature, $\mathrm{pH}$, stirring speed).

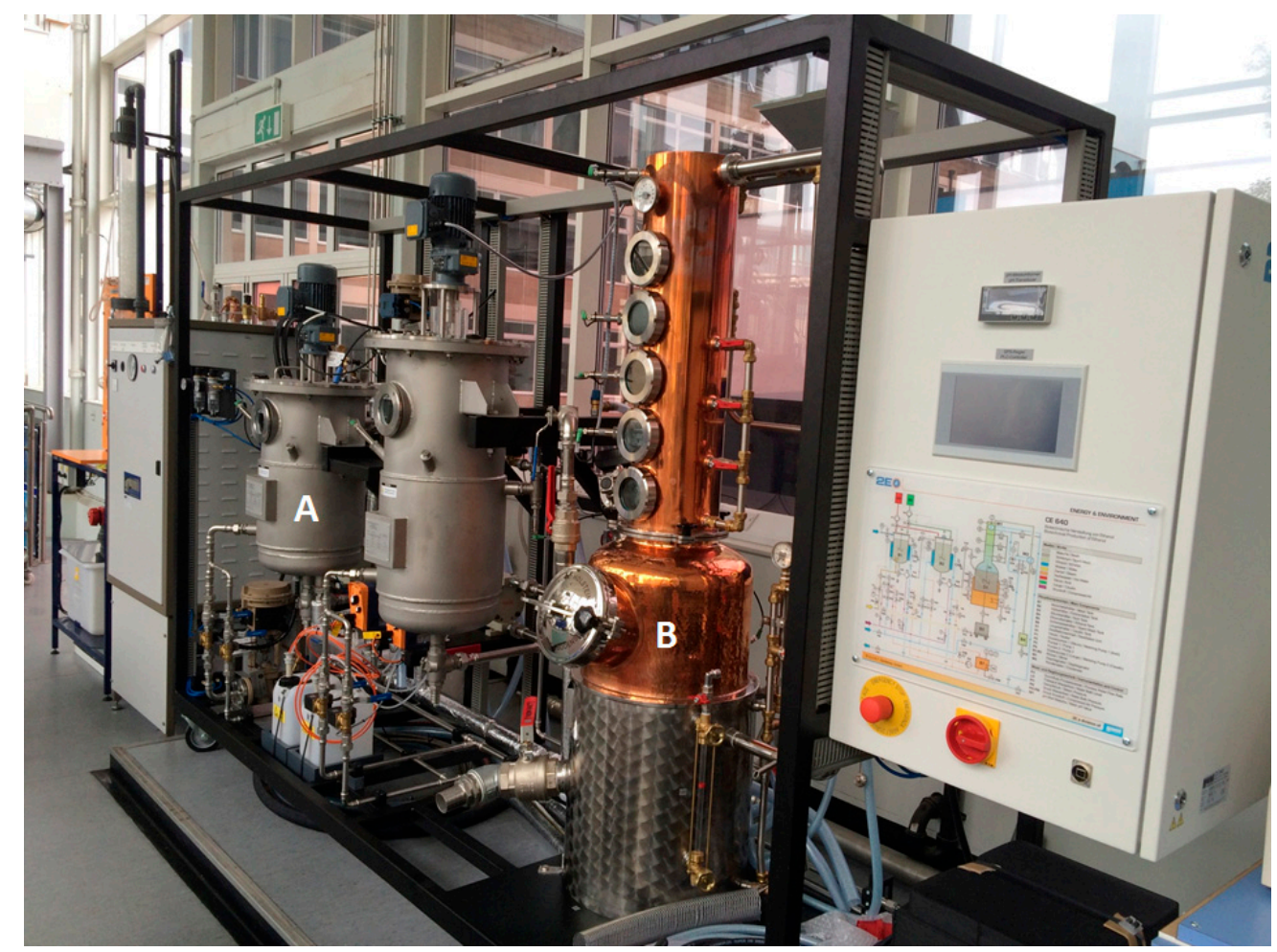

Figure 1. Extraction facility-(A) Extraction tank and (B) Distillation column.

\subsection{Isolation of Baobab Polysaccharides}

Figure 2 describes the isolation protocol used to extract polysaccharides from baobab leaves and fruits. A baobab sample $(1 \mathrm{~kg}$ ) was mixed with water (at a mass ratio of 1:25) and chemical reagents to control the $\mathrm{pH}$. The mixture was then added to the mash tank, where it was heated to $80^{\circ} \mathrm{C}$ for $1 \mathrm{~h}$ in the jacketed tank with continuous stirring, in order to carry out the aqueous extraction. To achieve a quicker result, a continuous steam injection was selected for heating, until the temperature reached the desired value. However, the jacket was also filled with hot water before the beginning of the process, in order to reduce the heat loss to the environment. 


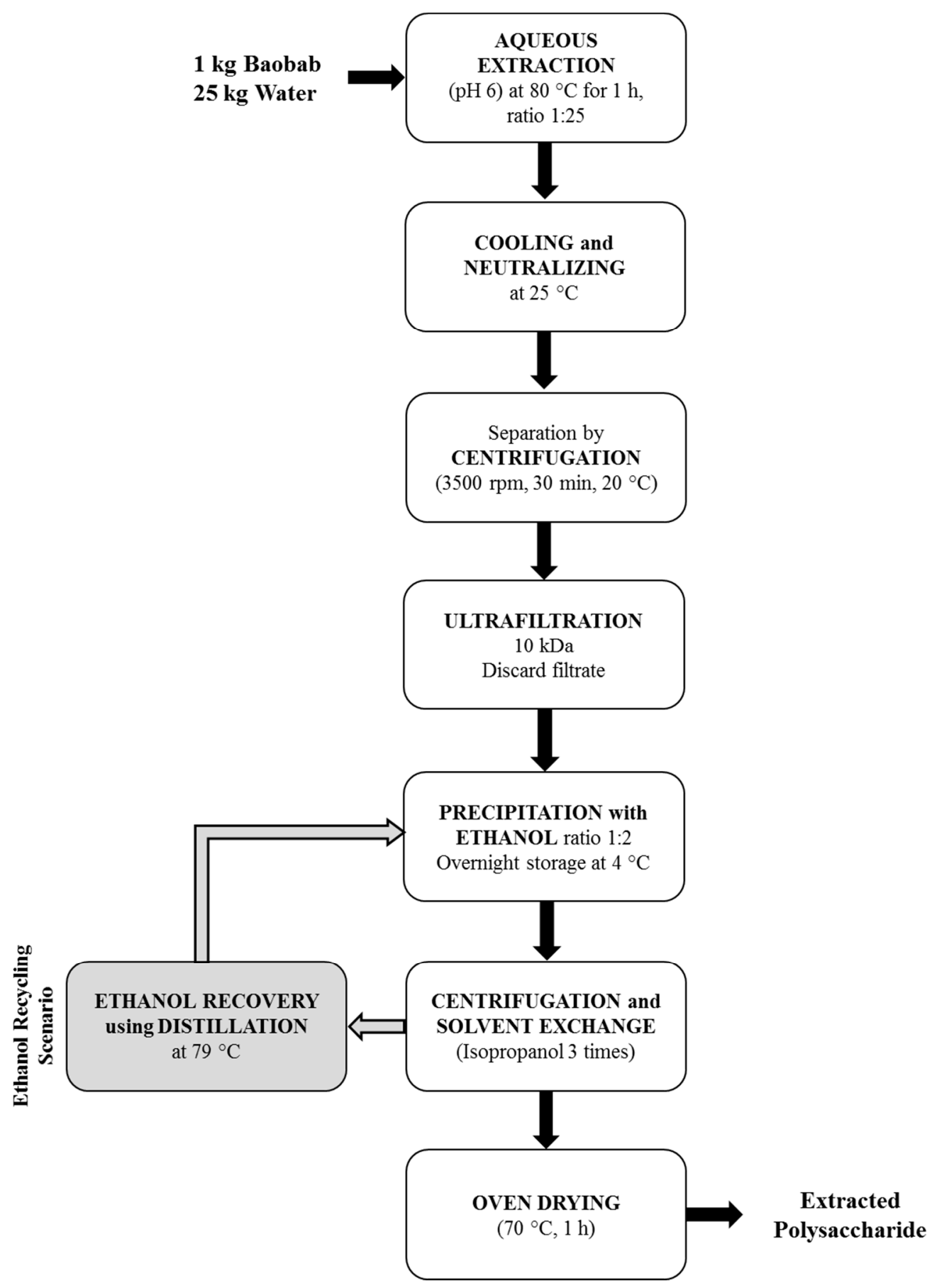

Figure 2. Isolation protocol of polysaccharides from baobab.

Subsequently, the extracted material was cooled down and neutralised at $25^{\circ} \mathrm{C}$. The next two steps involved the centrifugation and ultrafiltration of the mixture with a $10 \mathrm{kDa}$ molecular weight cut-off membrane in order to remove impurities and concentrate the extracted material. The extracted material was then mixed with ethanol at a 1:2 volume ratio and was stored overnight at $4{ }^{\circ} \mathrm{C}$, so that most alcohol insoluble solids can be obtained. Finally, the precipitate was centrifuged and washed with isopropanol and then oven dried at $70{ }^{\circ} \mathrm{C}$ for $1 \mathrm{~h}$. In order to improve the viability of the process, the recycling of the ethanol waste stream (Recycling Scenario in Figure 2), which was produced as a result of the precipitation, was examined. For that reason, the distillation column was operated (Figure 1B), to separate and obtain pure ethanol, which could then be reused in the precipitation step. 
Table 1 presents the yields and molecular weights of baobab polysaccharides that were extracted from the two different varieties of baobab leaves and fruits. Clearly, there was a significant difference in yield between leaves and fruits, which indicates structural variations of the polysaccharide backbone, as the same extraction protocol was followed for all samples. In addition, the weight-average molecular weight (Mw) was evaluated by size exclusion chromatography (SEC) coupled to a multi-angle light scattering detector (SEC-MALS). Polysaccharide solutions were filtered using a $0.45 \mu \mathrm{m}$ syringe filter before being injected [11]. It was visually observed that the polysaccharide extracted from the leaves were more viscous than those in fruits, as the molecular weight was higher. Since the fruits had a higher yield than the leaves, and since they are the only part of the plant that is approved for consumption in Europe (and, therefore, of economic significance), it was decided that the present work would focus on polysaccharides extracts from baobab fruits (which from here onwards will be referred to as baobab) and the technoeconomic assessment of this process.

Table 1. Yield and molecular weight of baobab polysaccharides extracted from baobab leaves and fruits.

\begin{tabular}{ccc}
\hline & $\begin{array}{c}\text { Baobab Polysaccharide (g Polysaccharide/100 g of } \\
\text { Dry Raw Material) }\end{array}$ & $\begin{array}{c}\mathbf{M}_{\mathbf{W}} \times \mathbf{1 0}^{\mathbf{3}} \\
\mathbf{( g / \mathbf { m o l } )}\end{array}$ \\
\hline Oval leaves & 2.4 & 605 \\
Oblong leaves & 6.0 & 704 \\
Oval fruit & 30.2 & 132 \\
Oblong fruit & 29.5 & 55 \\
\hline
\end{tabular}

\subsection{Technoeconomic Assessment}

The technoeconomic assesssment of the polysaccharide extraction process is performed in three steps. The first step includes a preliminary economic analysis of the bench scale extraction process, for both examined scenarios (with and without ethanol recycling). The assessment is based solely on the resources consumed during the experimental process and estimates the break-even price for the final product (the extracted polysaccharide), i.e., the minimum selling price that would achieve at least zero profit. If this price is comparable to the commercial prices of similar polysaccharides, then the corresponding scenarios are selected for the second step, the scale-up analysis.

The scale-up analysis is based on the approach presented in [14], which has been widely applied in various chemical engineering scale up studies. The scaled-up polysaccharide extraction process was evaluated for a 15-year project life time, assuming the plant to be operational for 330 days/year. Initially it is assumed that the plant will operate in the UK. Its economic assessment is based on the simple payback period. The target set is a payback period of six years, and the break-even price of the final product that can achieve that target is estimated. This price is again compared to the commercial prices of similar products. The scenario(s) that are found to be viable are then assessed in a Nigerian environment (third step). All assumptions remain the same, but the prices/costs are adapted to the local economy.

The assumptions used and the results of these three steps are presented in detail in the following three respective Sections 3.1-3.3.

\section{Results}

\subsection{Economic Analysis for the Bench Scale Extraction}

A preliminary economic analysis for both scenarios (with/without ethanol recycling) was been performed to determine the economic viability of the process, based on the bench scale extraction. In addition, Table 2 reports the operating costs of the raw materials, utilities and chemicals that were used during the extraction. The prices of the chemicals were extracted from the websites of common industrial suppliers for the largest quantity available, industrial use prices were assumed for the utilities, and the price of baobab for 
bulk purchase for the UK was quoted from an online seller (Source: Personal Communication in 2019). It was also assumed that steam is being produced onsite by a gas fired boiler with a typical efficiency of $85 \%$. Natural gas price was taken as $2 \mathrm{p}$ per $\mathrm{kWh}$ [15] whereas the calorific value was assumed to be $40 \mathrm{MJ} / \mathrm{m}^{3}$.

Table 2. Purchase price of raw materials, utilities, and chemicals.

\begin{tabular}{cc}
\hline Components/Utilities & Unit Price \\
\hline Baobab Fruits & $8 £ / \mathrm{kg}$ \\
Monosodium phosphate monohydrate & $17.54 £ / \mathrm{kg}$ \\
Disodium phosphate heptahydrate & $25.97 £ / \mathrm{kg}$ \\
Sodium azide & $80 £ / \mathrm{kg}$ \\
Ethanol & $2.84 £ / \mathrm{L}$ \\
Isopropanol & $2.19 £ / \mathrm{L}$ \\
Steam (3 bar) & $11.13 £ / \mathrm{m}^{3}$ \\
Water & $0.001 £ / \mathrm{L}$ \\
Electricity & $0.1 £ / \mathrm{kWh}$ \\
\hline
\end{tabular}

Table 3 presents the operating costs for each stage of the polysaccharide extraction and the overall cost for both scenarios (base case and with ethanol recycling). For the base scenario, the total operating cost is estimated to be $63.8 £ / \mathrm{kg}$ of raw material. It is observed that the most critical stages are the precipitation (accounting for $62 \%$ of the total cost), due to large amounts of alcohol used, and the extraction (23\%) stage. Finally, $13 \%$ is allocated to the pre-experiment stage, which includes the shipping costs of raw material. For the ethanol recycling scenario, the total processing cost is lower, reaching only $31.5 £ / \mathrm{kg}$ of raw material. In this case, the most critical steps are extraction ( $47 \%)$ and pre-experiment $(25 \%)$ with precipitation accounting only for $17 \%$ of the total cost.

Table 3. Operating costs (in $£ / \mathrm{kg}$ of processed baobab) per extraction stage.

\begin{tabular}{ccc}
\hline Stage & Base Scenario & Ethanol Recycling \\
\hline Pre-Experiment & 8.0 & 8.0 \\
Extraction & 31.9 & 31.9 \\
Centrifugation & 0.8 & 0.8 \\
Ultrafiltration & 0.3 & 0.3 \\
Precipitation & 39.6 & 5.5 \\
Centrifugation & 0.3 & 0.3 \\
Oven Drying & 0.1 & 0.1 \\
Distillation & 0.0 & 1.8 \\
Total Operating cost & 81.0 & 48.7 \\
\hline
\end{tabular}

Combining the operating cost with the average polysaccharide yield, which is approximately $300 \mathrm{~g} / \mathrm{kg}$ of raw material, the average cost per $100 \mathrm{~g}$ of extracted polysaccharide is estimated to be $21.1 £ / 100 \mathrm{~g}$, for the base scenario, and $10.4 £ / 100 \mathrm{~g}$, for the ethanol recycling scenario. These values correspond to the break-even price for the final product of the extraction process, i.e., the minimum price that the extracted polysaccharide could be sold, and at the same time the total cost and the total revenues would be equal. These values are similar to the price of commercially extracted pectin at large scale. However, they are much higher compared to the actual production cost of commercial pectin. For that purpose, a scale up analysis was performed, to assess if the overall cost would drop, and, thus, the potential profit of an industrial extraction plant would be higher, rendering such an investment viable.

\subsection{Profitability Analysis of a Scaled-Up Extraction Plant}

It was assumed that a batch process will operate at the facility, and the daily processed mass of baobab at the plant will be $100 \mathrm{~kg}$, with an expected yield of $30 \mathrm{~kg}$ of polysaccharide 
per day. The construction year was assumed to be 2018, with a construction period of six months. All the purchase costs for the plant were estimated according to [14] and calculated in British Pounds (E). Due to lack of data, the capital cost of the ultrafiltration unit was estimated from [16]. All capital costs have been brought forward for the construction year 2018 based on the Chemical Engineering Plant Cost Index. The indirect cost factors for the physical plant cost, the fixed capital cost, and the total investment required were also extracted from [14] and presented in Table 4.

Table 4. Indirect cost factors.

\begin{tabular}{cc}
\hline Physical Plant Cost Factors & \% of the Purchase Cost \\
\hline Equipment Erection & 0.4 \\
Piping & 0.7 \\
Instrumentation & 0.2 \\
Electrical & 0.1 \\
Buildings & 0.1 \\
Site Development & 0.05 \\
\hline Fixed Capital Cost Factors & \% of the Physical Plant Cost \\
\hline Design and Engineering & 0.3 \\
Contingencies & \% of the Fixed Capital Cost \\
\hline Total Investment Cost Factors & 0.05 \\
\hline Working Capital
\end{tabular}

Table 5 illustrates the purchase costs of the equipment (PCE), the physical plant cost (PPC), the fixed capital cost (FCE), and the total investment required for each of the two scenarios. Under ethanol recycling, all costs are slightly higher, as expected, because of the distillation column used to recover the ethanol.

Table 5. Total investment required for a scaled-up extraction plant (in $£ 2018$ ).

\begin{tabular}{ccc}
\hline Stage & Base Case $(\boldsymbol{E})$ & Ethanol Recycling $(\boldsymbol{E})$ \\
\hline Pre-Experiment & 18,100 & 18,100 \\
Extraction & 31,400 & 31,400 \\
Separation & 32,000 & 32,000 \\
Distillation & 0 & 17,800 \\
Storage/Miscellaneous & 37,700 & 37,700 \\
PCE & 119,200 & 137,000 \\
PPC & 304,200 & 349,600 \\
FCE & 426,000 & 489,500 \\
Total Investment & 447,300 & 514,000 \\
\hline
\end{tabular}

Regarding the operating and variable costs, all the relevant values for labour, facilitydependent costs (e.g., maintenance, depreciation, insurance, local taxes), and other miscellaneous costs were extracted from $[17,18]$ and are presented in Table 6 . The raw material, chemicals, and utilities prices presented in Table 2 were also used in this part of the analysis, whereas the basic labour rate was extracted from [19]. 
Table 6. Assumptions for variable costs calculations.

\begin{tabular}{cc}
\hline Labour & Assumption \\
\hline Tanks & 0.4 workers/unit/shift \\
Dryers & 0.5 workers/unit/shift \\
Ultrafiltration & 0.5 workers/unit/shift \\
Centrifuge & 0.5 workers/unit/shift \\
Grinder & 0.4 workers/unit/shift \\
Basic labour rate & $19(£ / \mathrm{h})$ \\
Supervision & $15 \%$ of total labour \\
Administration & $60 \%$ of total labour \\
Fringe benefits & $40 \%$ of total labour \\
\hline Labour & Assumption \\
\hline Maintenance & $10 \%$ of PPC \\
Insurance & $1 \%$ of FCE \\
Local taxes & $2 \%$ of FCE \\
Factory expenses & $5 \%$ of FCE \\
\hline Labour & Assumption \\
\hline Laboratory/QC/QA & $15 \%$ of total labour \\
\hline
\end{tabular}

Table 7 analyses the raw materials and utilities related annual costs for each scenario, highlighting the huge difference in the cost between the base case and the ethanol recycling scenario. Clearly, it can be observed that the subtotal for raw materials in the base case is almost four times higher $(1,834,500 £$ /year) than in the ethanol recycling scenario $(528,000 £ /$ year $)$. In contrast, the total value for utilities is slightly increased in the ethanol recycling scenario, due to the higher energy requirements as a result of the distillation column.

Table 7. Total annual variable costs (in $£ 2018$ /year).

\begin{tabular}{ccc}
\hline Stage & Base Case & Ethanol Recycling \\
\hline Raw Materials & $1,834,500$ & 528,000 \\
Baobab (incl. shipping cost) & 264,000 & 264,000 \\
Monosodium phosphate monohydrate & 171,900 & 171,900 \\
Disodium phosphate heptahydrate & 78,900 & 78,900 \\
Sodium azide & 13,200 & 13,200 \\
Ethanol & $1,126,000$ & $\mathrm{~N} / \mathrm{A}$ \\
Isopropanol & 180,500 & $\mathrm{~N} / \mathrm{A}$ \\
Utilities & 838,000 & 897,800 \\
Energy & 830,000 & 889,400 \\
Water & 8000 & 8400 \\
Labour & 474,000 & 544,000 \\
Facility & 64,500 & 74,000 \\
Miscellaneous & 105,000 & 121,000 \\
Total & $3,316,000$ & $2,164,800$ \\
\hline
\end{tabular}

Table 7 also summarises the raw material annual costs for each scenario as well as the utilities, the labour related and facility dependant annual operating costs for each scenario. Clearly, the ethanol recycling option and the subsequent addition of the distillation column increased the total utilities cost by approximately $10 \%$, because of the higher energy requirements. The labour and the facility-dependent costs also increased after the implementation of the ethanol recycling scenario. However, the total annual variable costs were decreased by approximately $35 \%$, due to the significant savings in solvent usage.

Since the polysaccharide extraction from baobab is a novel process, it is difficult and uncertain to assume a specific price for the final product in order to calculate the expected revenues and, thus, assess the economic viability of the investment. For that reason, the 
production cost of the polysaccharide was calculated for a minimum acceptable economic result, as expressed by the payback period, one of the most commonly used criteria for the economic performance assessment of a plant $[17,20]$. Table 8 summarises all the costs and the expected revenue from selling the final product for both scenarios, assuming corporation tax set at $30 \%$ and linear depreciation for the 15 years of the plant life. The minimum profitable selling price in determined for payback period of six years (which would give a return on investment of approximately $16.7 \%$ ).

Table 8. Profitability analysis.

\begin{tabular}{ccc}
\hline & Base Case & Ethanol Recycling \\
\hline Total Investment Required $(£)$ & 447,300 & 514,000 \\
Total Variable Costs $(£ /$ year $)$ & $3,316,000$ & $2,164,800$ \\
Total Revenue $(£ /$ year $)$ & $3,465,000$ & $2,336,000$ \\
Gross Profit $(£ /$ year $)$ & 149,000 & 171,300 \\
Taxes $(30 \%)$ & 44,700 & 51,400 \\
Depreciation & 29,800 & 34,300 \\
Net Profit & 74,500 & 85,600 \\
Simple Payback Period (year) & 6.00 & 6.00 \\
Minimum Selling Price $(£ / 100 \mathrm{~g})$ & 34.8 & 23.4 \\
\hline
\end{tabular}

The estimated minimum profitable selling price ranges between $£ 23$ and $£ 35$ per $100 \mathrm{~g}$ of polysaccharide and is comparable to the commercial selling price of high purity polysaccharides (£40-60/100 g) [21]. However, the commercial selling price varies depending on the functionality and may be lowered down to $£ 2 / 100 \mathrm{~g}$ (Source: Personal Communication with industrial pectin producer) for simple gelation applications. Considering that the two major components of the total annual variable costs are the raw materials (including shipping baobab from Nigeria to the UK) and the labour cost, it was decided to perform the scale-up analysis under Nigerian conditions, i.e., build the extraction plant closer to the source of the raw materials. This might make the investment more versatile, secure, and competitive in the long term, under the uncertainty of the market and the global economy and at the same time will have multiple benefits for the local economy and society.

\subsection{Scale up and Implementation in Africa}

Since the ethanol recycling scenario is more profitable than the base case, it was decided that only this one would be assessed for a potential scale-up installation in Nigeria. With respect to the purchase price of raw materials and utilities, appropriate values were used. When values in literature were found in Nigerian Naira (NGN), the conversion used is $£ 1=450 \mathrm{NGN}$.

Electricity prices in Nigeria range from $£ 0.01$ to 0.4 per $\mathrm{kWh}[22,23]$ and an average value of $£ 0.15$ per $\mathrm{kWh}$ was used for the analysis. Steam prices were considered to be equal to $£ 28.5$ per $\mathrm{m}^{3}$. It was assumed that steam is produced on site using a diesel boiler with a typical efficiency of $85 \%$. The price for diesel in Nigeria was taken as $£ 0.55$ per litre [24], with typical density of $0.85 \mathrm{~kg} / \mathrm{L}$ and calorific value of $45.5 \mathrm{MJ} / \mathrm{kg}$. Water price was assumed to be $0.125 p$ per L [25]. Finally, shipping costs for baobab were assumed to be equal to zero since the plant is going to be installed close to the baobab crop collection facilities.

The other two changes in the data used compared with the UK economic analysis were the labour cost, which was assumed to be $£ 0.5$ per hour [26] and the corporation tax was set at $32 \%$. The capital costs were initially assumed to be the same, since there were no detailed data for all the different components. However, a sensitivity analysis was performed to consider a potential over or underestimation of the total capital/installation cost. The minimum profitable selling price was again determined for payback period of six years (which would give a return on investment of approximately $16.7 \%$ ), and was found to be $£ 27$ per $100 \mathrm{~g}$. The value is comparable to the UK-based scenarios, meaning that the implementation of the plant is potentially viable and profitable in the Nigerian economy. 
Through the comparison presented in Table 9, it was observed that the major component that affected the final product prices, and, thus, the viability of the plant, was the cost of utilities (mostly steam).

Table 9. Total annual variable costs (in $£ 2018$ /year).

\begin{tabular}{ccc}
\hline Stage & Ethanol Recycling (UK) & Ethanol Recycling (NIG) \\
\hline Raw Materials & 528,000 & 264,000 \\
Utilities & 897,800 & $2,190,000$ \\
Labour & 544,000 & 14,000 \\
Facility & 74,000 & 74,000 \\
Miscellaneous & 121,000 & 75,000 \\
Total & $2,164,800$ & $2,617,000$ \\
\hline
\end{tabular}

For that reason and due to the uncertainties in the estimation of the economic input, a sensitivity analysis was performed to estimate the overall range of the final product price. Steam price, electricity price, and capital costs were chosen as the three uncertain variables. Five alternative values were chosen for each; the base value, $\pm 25 \%$ and $\pm 50 \%$ compared to the base value. The results presented in Figure 3 show that the impact of uncertainty in capital cost and price of electricity does not significantly affect the viability of the project. On the contrary, fluctuations in the steam price (and the respective fluctuations in the diesel price) play a critical role in the final decision. In the best-case scenario, the minimum profitable price might even drop below $£ 20 / 100 \mathrm{~g}$, leaving a bigger margin for profit and making the product more competitive than existing commercial products. Thus, it is critical to perform a more detailed market analysis regarding the steam producing unit and the fuel that would be used, considering not only the efficiency of the boiler but also parameters such as the stability of the price and its long-term variations. A biomass-fired boiler might be even considered an option in this case, with slightly lower overall efficiency but also locally sourced and cheaper fuel [27].

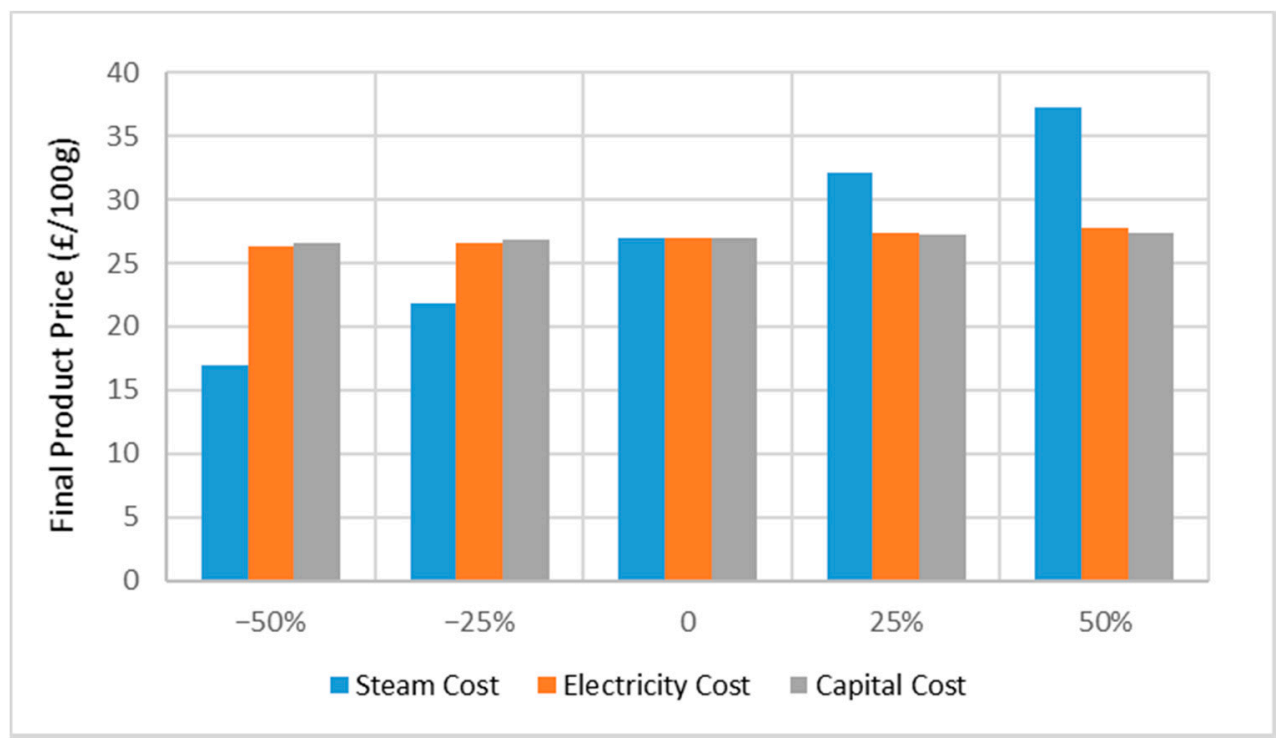

Figure 3. Sensitivity analysis for the final product price.

\section{Discussion}

An economic viability assessment was performed for the isolation and extraction of baobab polysaccharides on a large scale and the potential market for such products were examined. As the extraction process uses large amounts of ethanol for the polysaccharide precipitation (accounting for $62 \%$ of the total cost), this allows the opportunity to investigate two alternative scenarios: a base case (without ethanol recycling) and a circular scenario 
with ethanol recycling. For this reason, a preliminary economic analysis for both scenarios (with/without ethanol recycling) was performed to determine the economic viability of the process, based on the bench scale extraction and considering all the capital and operating costs. The results showed that the average cost per $100 \mathrm{~g}$ of extracted polysaccharide was estimated to be $33.9 £ / 100 \mathrm{~g}$, for the base scenario, and $22.5 £ / 100 \mathrm{~g}$, for the ethanol recycling scenario by combining the operating cost with the average polysaccharide yield. The values were similar to the price of commercial pectin; however, they were higher compared to the actual production cost of commercial pectin. In addition, a scale up analysis was evaluated for a 15-year project lifetime, to assess if the overall cost would drop, and, thus, the potential profit of an industrial extraction plant would be higher, rendering such an investment viable.

However, as the polysaccharide extraction from baobab is a novel process, it was difficult and uncertain to assume a specific price for the final product in order to calculate the expected revenues and, thus, assess the economic viability of the investment. For that purpose, the production cost of the polysaccharide was calculated for a minimum acceptable economic result, as expressed by the payback period. The minimum profitable selling price was estimated to be between $£ 22$ and $£ 34$ per $100 \mathrm{~g}$ of polysaccharide, which was comparable to the commercial selling price of high purity polysaccharides. Since the two major components of the total annual variable costs were the raw materials and the labour cost, a scale-up analysis with the ethanol recycling scenario was examined under Nigerian conditions, as it was the most profitable.

In addition, a sensitivity analysis was performed to estimate the overall range of the final product price. The major component that affects the final product prices and, thus, the viability of the plant, was the cost of utilities and mostly steam. The results revealed that fluctuations in the steam price play a critical role although the best-case scenario showed that the minimum profitable price might even drop below $£ 20 / 100 \mathrm{~g}$, leaving a bigger margin for profit and making the product more competitive to existing commercial ones. On this basis, a more detailed analysis on a case-by-case basis is necessary to investigate more accurate values for purchase costs as well as alternative options for steam production in order to optimize the baobab polysaccharide extraction process and to establish a profitable price of baobab polysaccharide as a food or pharmaceutical ingredient.

Author Contributions: Conceptualization, A.A.-D. and V.K.; methodology, A.A.-D. and M.D. and V.K.; software, A.A.-D.; validation, M.D. and A.A.-D.; formal analysis, M.D. and A.A.-D.; investigation, M.D. and A.A.-D.; resources, V.O. and K.F.; writing-original draft preparation, A.A.-D.; writing-review and editing, M.D., V.K., K.F. and A.M.S.; visualization, A.A.-D. All authors have read and agreed to the published version of the manuscript.

Funding: This research received no external funding.

Acknowledgments: Author K. O. Falade is grateful to the Commonwealth Scholarship Commission, NGCN-2018-237 for the Splite-site Scholarship utilised by Vivian Offiah to carry out the research.

Conflicts of Interest: The authors declare no conflict of interest.

\section{References}

1. Namratha, V.; Sahithi, P. Baobab: A review about "the tree of life". Int. J. Adv. Herbal Sci. Technol. 2015, 1, 20-26.

2. Ismail, B.B.; Pu, Y.; Guo, M.; Ma, X.; Liu, D. LC-MS/QTOF identification of phytochemicals and the effects of solvents on phenolic constituents and antioxidant activity of baobab (Adansonia digitata) fruit pulp. Food Chem. 2019, 277, 279-288. [CrossRef] [PubMed]

3. FDA Agency Response Letter GRAS Notice, No. GRN 000273. Available online: http://www.fda.gov/food/ingredientspackaginglabeling/ gras/noticeinventory/ucm174945.htm/ (accessed on 20 November 2019).

4. Donkor, A.M.; Addae, D.; Kpoanu, J.E.; Kankam, F.; Boaudi, A.N.; Abanya, E.Y.M. Antioxidant enrichment of baobab fruit pulp treated with oil extracted from the seeds. Food Nutr. Sci. 2014, 5, 328-333. [CrossRef]

5. Ibrahima, C.; Didier, M.; Max, R.; Pascal, D.; Benjamin, Y.; Renaud, B. Biochemical and nutritional properties of baobab pulp from endemic species of Madagascar and the African mainland. Afr. J. Agric. Res. 2013, 8, 6046-6054.

6. Rahul, J.; Jain, M.K.; Singh, S.P.; Kamal, R.K.; Anuradha, N.A.; Gupta, A.K.; Mrityunjay, S.K. Adansonia digitata L. (baobab): A review of traditional information and taxonomic description. Asian Pac. J. Trop Biomed. 2015, 5, 79-84. [CrossRef] 
7. Kamatou, G.P.P.; Vermaak, I.; Viljoen, A.M. An updated review of Adansonia digitata: A commercially important African tree. S. Afr. J. Bot. 2011, 77, 908-919. [CrossRef]

8. Muthai, K.U.; Karori, M.S.; Muchugi, A.; Indieka, A.S.; Dembele, C.; Mng'omba, S.; Jamnadass, R. Nutritional variation in baobab (Adansonia digitata L.) fruit pulp and seeds based on Africa geographical regions. Food Sci. Nutr. 2017, 5, 1116-1129. [CrossRef] [PubMed]

9. Sokeng, A.J.T.; Sobolev, A.P.; Di Lorenzo, A.; Xiao, J.; Mannina, L.; Capitani, D.; Daglia, M. Metabolite characterization of powdered fruits and leaves from Adansonia digitata L. (baobab): A multi-methodological approach. Food Chem. 2019, 272, 93-108. [CrossRef] [PubMed]

10. Aduna Ltd-Our Mission. Available online: https://aduna.com/pages/our-mission (accessed on 20 March 2020).

11. Alba, K.; Offiah, V.; Laws, A.P.; Falade, K.; Kontogiorgos, V. Baobab polysaccharides from fruits and leaves. Food Hydrocolloid 2020, 106, 105874. [CrossRef]

12. Dimopoulou, M.; Alba, K.; Campbell, G.; Kontogiorgos, V. Pectin recovery and characterization from lemon juice waste streams. J. Sci. Food Agr. 2019, 99, 6191-6198. [CrossRef] [PubMed]

13. Dimopoulou, M.; Kontogiorgos, V. Soluble dietary fibres from sugarcane bagasse. Int. J. Food Sci. Tech. 2020, 55, 1943-1949. [CrossRef]

14. Sinnott, R.K. Coulson and Richardson's Chemical Engineering Series: Volume 6 Chemical Engineering Design, 4th ed.; ButterworthHeinemann: Oxford, UK, 2005.

15. Prices of Fuels Purchased by non-Domestic Consumers in the UK, Revised Data for Q1 2018 and New Data for Q2 2018. Available online: https: / / www.gov.uk/government/statistical-data-sets/gas-and-electricity-prices-in-the-non-domestic-sector (accessed on 15 December 2019).

16. Guo, T.; Englehardt, J.; Wu, T. Review of cost versus scale: Water and wastewater treatment and reuse processes. Water Sci. Technol. 2014, 69, 223-234. [CrossRef] [PubMed]

17. Peters, M.S.; Timmerhaus, K.D.; West, R.E. Analysis of Cost Estimation, in Plant. Design and Economics for Chemical Engineers, 5th ed.; McGraw-Hill: Boston, MA, USA, 2003.

18. Misailidis, N.; Campbell, G.M.; Du, C.; Sadhukhan, J.; Mustafa, M.; Mateos-Salvador, F.; Weightman, R.M. Evaluating the feasibility of commercial arabinoxylan production in the context of a wheat biorefinery principally producing ethanol: Part 2. Process simulation and economic analysis. Chem. Eng. Res. Des. 2009, 87, 1239-1250. [CrossRef]

19. Labour Market Overview, UK Statistical Bulletins. Available online: https://www.ons.gov.uk/employmentandlabourmarket/ (accessed on 20 November 2019).

20. Douglas, L.E. Industrial Chemical Process. Design, 2nd ed.; McGraw-Hill: New York, NY, USA, 2014.

21. Prices for Pectin from Citrus Peel and from Apple. Available online: https://www.sigmaaldrich.com/ (accessed on 31 March 2020).

22. Lamidi, R.O.; Jiang, L.; Wang, Y.; Pathare, P.B.; Aguilar, M.C.; Wang, R.; Eshoul, N.M.; Roskilly, A.P. Techno-Economic Analysis of a Cogeneration System for Post-Harvest Loss Reduction: A Case Study in Sub-Saharan Rural Community. Energies 2019, 12, 872. [CrossRef]

23. Lamidi, R.O.; Wang, Y.; Pathare, P.B.; Roskilly, A.P.; Aguilar, M.C. Biogas Tri-generation for Postharvest Processing of Agricultural Products in a Rural Community: Techno-economic Perspectives. Energy Proced. 2017, 142, 63-69. [CrossRef]

24. Diyoke, C.; Idogwu, S.; Ngwaka, U.C. An Economic Assessment of Biomass Gasification for Rural Electrification in Nigeria. Int. J. Renew. Energy Tech. Res. 2014, 3, 1-17.

25. Girei, A.A.; Audu, S.I.; Onuk, E.G.; Ismail, Z.M. Why the Economics of Groundnut Processing in Akwanga Local Government Area, Nasarawa State, Nigeria. Econ. Eng. Agric. Rural Dev. 2016, 16, 103-110.

26. Nigeria Labour Costs. Available online: https:/ / tradingeconomics.com/ (accessed on 20 November 2019).

27. Sobamowo, G.M.; Ojolo, S.J. Techno-Economic Analysis of Biomass Energy Utilization through Gasification Technology for Sustainable Energy Production and Economic Development in Nigeria. J. Energy 2018, 2018, 4860252. [CrossRef] 